\title{
A PRELIMINARY STUDY OF HEALTH PROBLEMS AMONG CONSTRUCTION WORKERS IN MALAYSIA
}

\author{
Nurshuhada Zainon, Loo Siaw Chuing, F.A. Mohd-Rahim, Nur Mardhiyah Aziz, Che Wan Nor \\ Shahirah Che Wan Ahmad Pauzi
}

Project Management, Procurement \& Economics Research Group, Centre of Building, Construction \& Tropical Architecture, Faculty of Built Environment, University of Malaya, 50603 Kuala Lumpur.

*Corresponding author: siawchuing@um.edu.my

\begin{abstract}
The Department of Occupational, Safety and Health reported that out of 172 investigated construction accidents in $2014,42 \%$ involved death. Although this rate is lower than that for manufacturing plants, lost work-day rates are higher for several individual construction trades and for certain types of injuries. Since the lost work-day rates for small to medium sized construction companies are higher than that of similar-sized manufacturing plants, it will cause economic loss to the construction companies more than the others. Studies have found that health conditions also contribute to construction safety issues. These raise questions about the health level among construction workers in Malaysia prior to looking at their effects onto construction safety issues. Therefore, this preliminary study aims to identify health issues among them. A total of 335 respondents responded to a survey distributed among construction workers. It was found that the top health problems recorded to affect the workers were musculoskeletal disorder, eyes, nose and throat problem, fatigue and headache. The findings provided a further insight on the seriousness of certain types of health problems that affect construction workers working in the construction industry, hence medical cost or insurance should be an important cost element that needs to be considered by a Quantity Surveyor in building up a project cost.
\end{abstract}

Keywords: Health, Safety, Construction Workers, Malaysia.

\section{INTRODUCTION}

Construction industry is a booming industry for developing countries. The industry has immense continuous potential in generating a tremendous amount of employment, accounting to around $7 \%$ of the total employed workforce around the globe (Economy Watch, 2010). The rapid development of construction industry relies on construction productivities, which in turn concerns with health conditions of the construction workers. Construction productivities are very much dependent on the workers' health, adequate nutrition and industrial discipline because these determine the predictable availability of labor (Thomas \& Frankenberg, 2002).

Construction sector is highly risky due to its production processes and labor-intensive characteristic. Owing to that, occupational accidents bring the sector up against large-scale financial loss. Each year in the British construction sector, around $3 \%$ of workers suffer from an illness they believed to be work-related and $3 \%$ of workers sustain a work-related injury, leading to 1.7 million working lost days (Health and Safety Executive, 2015). In Turkey, the cost of workday loss caused by major occupational accidents is USD19,431.75 and minor occupational accidents caused a loss of USD6,924.25. The costs of workday loss caused by minor occupational accidents are almost $35 \%$ of major workday losses (Yilmaz \& Çelebi, 2015). These costs elicit the importance of preventive measures for workers' health and safety in construction.

In the Malaysian context, a database on construction workers' health statistic is still lacking. Prior to understanding how does safety and health influence Malaysian construction sector, it is important to first determine the common health issues among construction workers. The findings are believed to be crucially useful in ascertaining the financial analysis for construction companies. Therefore, this paper aims to identify the common health problems among construction workers who are working in the construction environment in Malaysia. 


\section{LITERATURE REVIEW}

Construction sector is widely recognized as the sector with high accident rates due to its working nature that needs to deal with heights, involve electrical tools, expose to harmful chemicals, noise, vibration as well as uncomfortable temperature. Having to work in such environment, several health problems such as dermatitis, hearing loss and whole-body vibration are increasingly evident among the construction workers. This scenario has motivated researchers around the world to carry out study to enhance their understanding relating to health issues among construction workers. Research conducted in Malaysia by Ali, Kamaruzzaman and Sing (2010), Hamid, Majid and Singh (2008), and Zakaria, Mansor and Abdullah (2012) showed that that the main causes of accidents at construction sites were workers' negligence, failure to obey the work procedures, work at high elevation, operate equipment without safety devices, poor site management and low skill and knowledge. Findings showed that the construction workers who lost their concentration during work and felt fatigue due to poor health conditions had led to higher chances of getting into work accidents.

Another study on port site accidents by Mansor, Zakaria and Abdullah (2011) focused on two common dimensions of workplace accidents, namely individual and job-related factors. Using 177 surveyed samples, correlation test results showed that stress and fatigue, unsafe action, machinery and tools, design of workplace, training procedures were the significant factors that had contributed to workplace accidents. Goldenhar et al. (2003) conducted an exploratory ethnographic study to examine the relationship between working overtime and health and safety in construction industry. Focus groups undertaken with 64 construction workers in the United States indicated that health and safety issues were their primary concerns. However, they also raised concerns related to working overtime and the effects of working overtime. Research had also been carried out among the German construction workers, and the findings revealed an increasing number of respiratory problems, cancer and musculoskeletal disorders (Arndt et al., 2005). Stocks et al., (2010) also reported an increasing number of contact dermatitis, mesothelioma, lung cancer, skin neoplasia, benign pleural disease and pneumoconiosis among the UK construction workers. Other than physical health issue, there is a recent research on prevalence of mental health complaints among the construction workers. Boschman et al. (2013) measured the mental health effect among bricklayers and construction supervisors. They then discovered that high working speed and quantity were associated with symptoms of depression for both professions. Low level of decision-making and social support from the direct supervisor were also associated with symptoms of depression among construction supervisors.

The impact of health and safety hazards for construction workers in developing countries is 10 to 20 times higher compared to the other countries (Tadesse \& Israel, 2016). Thus, understanding the construction workers' health problem is crucial for prevention and mitigation measures.

The review of literature related to construction worker health issues has revealed 13 health problems. Table 1 shows the many potential health problems that have been reported to be affecting construction workers. These problems were also surveyed among the construction workers in this study.

Table 1: Health problems among construction workers

\begin{tabular}{ll}
\hline \multicolumn{1}{c}{ Health problem } & \multicolumn{1}{c}{ Source } \\
\hline Cardiovascular & Cavallari, Fang, Eisen, Mittleman, \& Christiani, 2016 \\
Eye strain & Hsu, Sun, Chuang, Juang, \& Chang, 2008; Jafari \& Dehghani, \\
Fatigue & 2016 \\
Hand-arm vibration syndrome & Hsu et al., 2008 \\
Hearing disability syndrome & Sauni, Toivio, Esko, Pääkkönen, \& Uitti, 2015 \\
Insomnia and depression & House, Sauvé, \& Jiang, 2010 \\
Occupational lung cancer & Hu, Liang, Hu, Long, \& Ge, 2013 \\
Respiratory problems & Lacourt, Pintos, Lavoué, Richardson, \& Siemiatycki, 2015 \\
Sick building syndrome & Baker, Dagg, \& Greene, 1985 \\
Skin cancer & Jafari \& Dehghani, 2016 \\
Stress & Stocks et al., 2011 \\
Sunburn & Leung, Liang, \& Yu, 2016 \\
Work-related musculoskeletal disorder & Serrano, Cañada, \& Moreno, 2013 \\
\hline
\end{tabular}




\section{METHODOLOGY}

A questionnaire survey was conducted to gather information on the health conditions of the construction workers working in the construction environment in Malaysia. This study investigated whether they had experienced the health problems raised. The questionnaire was prepared based on the objective to determine the health problems that affect the construction workers in their working environment at all levels of work. Construction workers encompassed many levels of work organizations, including top, middle and lower organization. Top organization comprised directors, project managers and manager assistants. Middle organization comprised project consultants, assistant project consultants, engineers, architects and contractors. Lastly, lower organization in construction work level comprised general labors and unskilled labors.

The types of questions asked in the survey were categorical questions. The questionnaire was divided into two main parts; part 1 on background of the respondents, and part 2 on current health conditions of the respondents when working on construction projects. The questions were close-ended questions as they were much more efficient for data collection, processing and analysis (Bourque, et al., 2003) and sentences used were simple and short to improve response rates (Dillman, 2000) especially when general labors and unskilled labors were involved. The questionnaire was also found to have reasonable internal consistency reliability with scores of above 0.70 after assessment using Cronbach's alpha coefficient (Nunnally \& Bernstein, 1994).

A total of 500 online surveys were randomly sent to G1 until G7 construction companies in the whole of Malaysia. However, in a period of the survey ( 2 months), only 53 responses were received. Another 500 self-administered and postal questionnaire surveys were then distributed to construction firms and their site offices located in Kuala Lumpur, Johor and Penang (3 prominent states in West Malaysia). A total of 282 responses were subsequently received, giving a total of 335 respondents. Therefore, this makes up a response rate of $33.5 \%$ (see Table 2). According to Sekaran and Bougie (2010), response rate of $30 \%$ is deemed acceptable for further analysis.

Table 2: Response rate of the questionnaires

\begin{tabular}{lcc}
\hline Response & Frequency/Rate \\
\hline Number of distributed & 1000 \\
questionnaires & 335 \\
Returned questionnaires & $33.5 \%$ \\
Response rate & \\
\hline
\end{tabular}

\section{RESULTS}

Demographic information collected during the survey $(n=335)$ (refer Table 3 ) showed that majority of respondents were female (60.6\%). Respondents' age younger than 20 years $(0.3 \%), 20$ to 29 years $(39.1 \%), 30$ to 39 years (14.5\%), 40 to 49 years $(15.5 \%)$, and older than 49 years $(30.6 \%)$. Employees described their positions and responsibilities as managerial-executive (most time based in offices) (78.8\%), supervisor on site (14.0\%), support staff on site (3.0\%), and blue-collared labour (interviewed at site) (4.2\%). Most of the respondents worked for 10 to 19 years in the construction industry $(43.9 \%)$, followed by less than 5 years $(36.1 \%)$, between 5 to 9 years $(12.7 \%)$, between 20 to 29 years $(6.7 \%)$, and lastly more than 29 years $(0.6 \%)$. Overall, $96.4 \%$ of employees reported good and excellent health condition with others having their health under certain medication.

Table 3: Respondents' Profile

\begin{tabular}{|c|c|c|}
\hline Respondents Profile & $\begin{array}{c}\text { Frequency } \\
(\boldsymbol{n = 3 3 5})\end{array}$ & Percent \\
\hline Gender & 203 & 39.4 \\
Male & 132 & 60.6 \\
Female & 1 & 0.3 \\
\hline Age & 131 & 39.1 \\
$<20$ & 49 & 14.5 \\
$20-29$ & 52 & 15.5 \\
$30-39$ & 103 & 30.6 \\
$40-49$ & & \\
$>49$ & & \\
\hline Occupation (Position)
\end{tabular}




\begin{tabular}{|l|c|c|}
\hline Managerial-executive & 264 & 78.8 \\
Supervisor on site & 47 & 14.0 \\
Support staff on site & 10 & 3.0 \\
Blue-collared labour & 14 & 4.2 \\
\hline Working Experience & & \\
< 5 years & 121 & 36.1 \\
$5-9$ years & 43 & 12.7 \\
$10-19$ years & 147 & 43.9 \\
$20-29$ years & 22 & 6.7 \\
> 29 years & 2 & 0.6 \\
\hline Health Condition & 323 & 96.4 \\
Good and Excellent & 12 & 6.7 \\
Under Medication & & \\
\hline
\end{tabular}

This paper describes the health problems occurring among the construction workers based on percentage; below $10 \%$ as minor cases (less than $3 \%$ is classified as very minor), $10 \%$ to $20 \%$ as moderate cases, and lastly more than $20 \%$ as major or top cases (refer Table 4).

Table 4: Classification of health problems

\begin{tabular}{lc}
\hline Percentage & Classification \\
\hline$<3 \%$ & Very minor case \\
$<10 \%$ & Minor case \\
$10-20 \%$ & Moderate case \\
$>30 \%$ & Major case \\
\hline
\end{tabular}

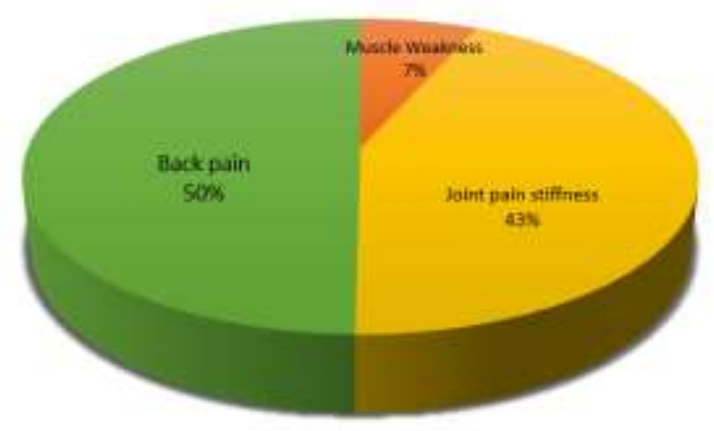

Figure 1: Percentage distribution of MSDs

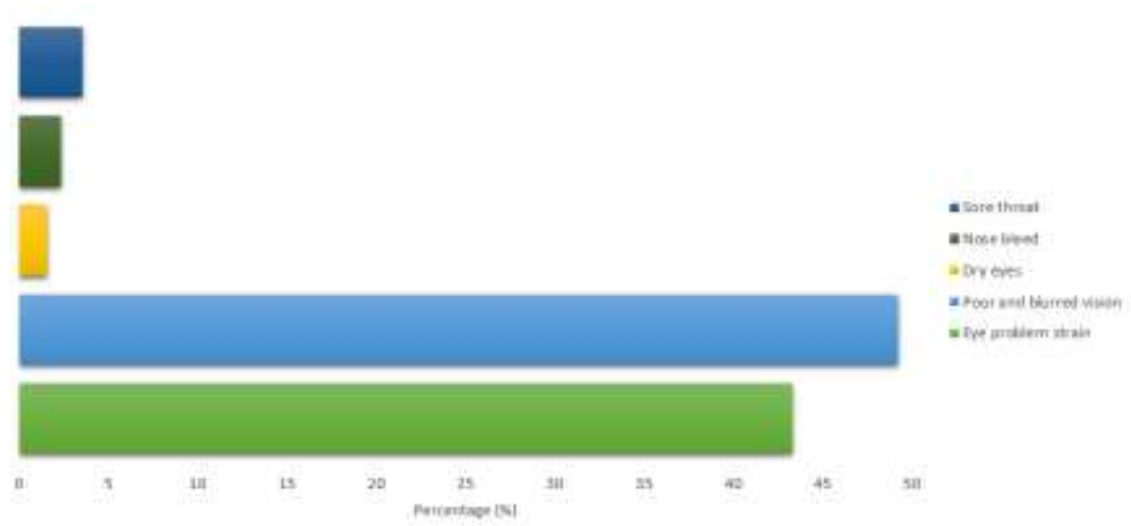

Figure 2: Percentage distribution of ENT disease 
One of the major health diseases found is musculoskeletal disorders (MSDs) (see Figure 1) that can affect anyone due to unbalanced lifestyle and working habits. For example, when a worker is doing desk job every day for a long period of time, he is likely to suffer back pain. MSDs are common found to be affecting construction workers as well. MSDs topped the list where there were 127 respondents suffered back pain, 111 had joint pain stiffness, and only 17 respondents had muscle weakness; making a total of 255 (76.1\%) MSD patients. A total of 254 (75.8\%) respondents recorded to suffer eye, nose and throat (ENT) diseases with majority suffering eye problem like eye strain $(n=110)$, poor or blurred vision $(n=125)$, and dry eyes $(n=4)$. Other ENT problems suffered by respondents were nose bleeds $(n=6)$ and sore throats $(n=9)$ (refer Figure 2). Another two top common diseases were fatigue $(\mathrm{n}=169 ; 50.4 \%)$ and headaches $(\mathrm{n}=134 ; 40.0 \%)$.

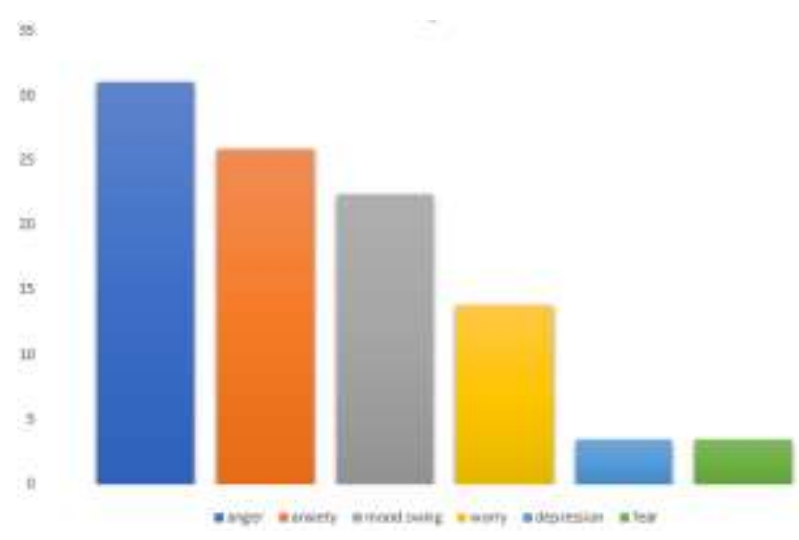

Figure 3: Percentage distribution of Emotions

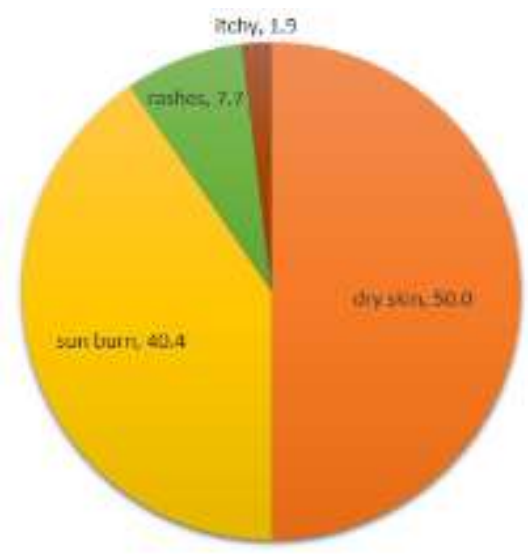

Figure 4: Percentage distribution of Skin/Dermatology

Emotions $(n=58 ; 17.3 \%)$ and skin/dermatology $(n=52 ; 15.5 \%)$ were also moderately common among construction workers. Six kinds of emotion problems were surveyed. Among the 58 who suffered emotional problems, 18 had anger issues, 15 had anxiety, 13 had mood swings, 8 had ongoing worry, and lastly 2 each had depression and fear (see Figure 3). There were four types of skin problems surveyed. Among the 52 respondents, 26 reported to suffer from dry skin, 21 sunburn, 4 rashes, and 1 itchy skin (see Figure 4).

In this study, there were 14 out of 20 diseases surveyed that fell under the category of minor cases with less than $10 \%$ of occurrence. There were $25(7.5 \%)$ female construction workers suffered female problems like cramps or backache $(n=15)$, pre-menstrual emotions $(n=8)$, and painful menstrual periods $(n=2)$. This was followed by poor memory $(n=23 ; 6.9 \%)$, decreased motivation $(n=19 ; 5.7 \%)$, and insomnia $(n=16 ; 4.8 \%)$. There were $14(4.2 \%)$ cases of cardiovascular diseases occurring among construction workers where 6 had high blood pressure, 3 each had low blood pressure and chest pain or pressure, and 2 had irregular heartbeat. Hand Arm Vibration (HAV) occurred among 13 (3.9\%) respondents; majority suffered from numbness of fingers $(n=10)$ and others suffered difficulty to pick very small objects $(n=3)$. Only $12(3.6 \%)$ construction-related employees experienced abnormal sweating. Noise-induced hearing loss (NIHL) risks any construction workers who are constantly working on construction site. NIHL problems include ringing in the ears, poor hearing, need to repeat multiple times and need to turn audio volume high. In total, there were $11(3.3 \%)$ respondents suffered NIHL with 2 had ringing in ears, 2 had poor hearing, 6 needed repeated instructions during work, and 1 needed high audio volume.

There were 6 out of the said 14 minor diseases that fell under the very minor category of less than $3 \%$ of occurrence. A total of $9(2.7 \%)$ respondents were recorded to suffer from Sick Building Syndrome (SBS). SBS includes several symptoms, when one is in a certain building, such as feeling dizzy $(n=7)$, feeling nausea $(n=1)$, and being sensitive to odors and sights $(n=1)$. Respiratory problems are health diseases that can occur from exposure to harmful particles at construction sites. Even though construction sites expose workers to dust, surprisingly, only 8 (2.4\%) respondents claimed to have respiratory problems like cough $(n=6)$, asthma $(n=1)$, and difficult breathing $(n=1)$. There were $7(2.1 \%)$ respondents who suffered from gastrointestinal problems with 5 having gastrointestinalrelated nausea and 2 having poor appetite. The last three diseases occurring among construction workers were difficulty to focus $(n=6 ; 1.8 \%)$, tendency to faint $(n=2 ; 0.6 \%)$, and difficulty to walk or move for long hours $(n=1$; $0.3 \%$ ). 
Table 5 shows ranking and frequency of the diseases occurred among construction workers.

Table 5: Frequency distribution of diseases and their classifications

\begin{tabular}{|c|c|c|c|c|c|}
\hline \multirow{2}{*}{ Diseases } & \multicolumn{2}{|c|}{ Frequency } & \multirow{2}{*}{$\begin{array}{l}\text { Percentage } \\
(\%)\end{array}$} & \multirow{2}{*}{ Classifications } & \multirow{2}{*}{ Rank } \\
\hline & Yes & No & & & \\
\hline $\begin{array}{l}\text { Musculoskeletal } \\
\text { (MSDs) }\end{array}$ & 255 & 80 & 76.1 & Major case & 1 \\
\hline Eyes, nose and throat (ENT) & 254 & 81 & 75.8 & Major case & 2 \\
\hline Fatigue & 169 & 166 & 50.4 & Major case & 3 \\
\hline Headaches & 134 & 201 & 40.0 & Major case & 4 \\
\hline Emotions & 58 & 277 & 17.3 & Moderate case & 5 \\
\hline Skin/Dermatology & 52 & 283 & 15.5 & Moderate case & 6 \\
\hline Female problems & 25 & 310 & 7.5 & Minor case & 7 \\
\hline Poor memory & 23 & 312 & 6.9 & Minor case & 8 \\
\hline Decreased motivation & 19 & 316 & 5.7 & Minor case & 9 \\
\hline Insomnia & 16 & 319 & 4.8 & Minor case & 10 \\
\hline Cardiovascular & 14 & 321 & 4.2 & Minor case & 11 \\
\hline Hand arm vibration (HAV) & 13 & 322 & 3.9 & Minor case & 12 \\
\hline Abnormal sweating & 12 & 323 & 3.6 & Minor case & 13 \\
\hline $\begin{array}{l}\text { Noise-induced hearing loss } \\
\text { (NIHL) }\end{array}$ & 11 & 324 & 3.3 & Minor case & 14 \\
\hline Sick Building Syndrome (SBS) & 9 & 326 & 2.7 & $\begin{array}{l}\text { Very minor } \\
\text { case }\end{array}$ & 15 \\
\hline Respiratory problem & 8 & 327 & 2.4 & $\begin{array}{l}\text { Very minor } \\
\text { case }\end{array}$ & 16 \\
\hline Gastrointestinal & 7 & 328 & 2.1 & $\begin{array}{l}\text { Very minor } \\
\text { case }\end{array}$ & 17 \\
\hline Difficulty to focus & 6 & 329 & 1.8 & $\begin{array}{l}\text { Very minor } \\
\text { case }\end{array}$ & 18 \\
\hline Tendency to faint & 2 & 333 & 0.6 & $\begin{array}{l}\text { Very minor } \\
\text { case }\end{array}$ & 19 \\
\hline $\begin{array}{l}\text { Difficulty to walk or move in } \\
\text { long hours }\end{array}$ & 1 & 334 & 0.3 & $\begin{array}{l}\text { Very minor } \\
\text { case }\end{array}$ & 20 \\
\hline
\end{tabular}

\section{DISCUSSION}

This study concentrated on finding out whether all levels of construction workers were facing work-related health problems. The major health problems, where more than $70 \%$ of the respondents encountered, were musculoskeletal disorders and eyes, nose and throat diseases. These were followed by fatigue (50.4\%) and headache (40.0\%). These implied that majority of the construction workers were overworked and mostly deprived of rests. The findings concurred with major findings of related studies where higher chances of work accidents may occur as the workers suffered MSDs, fatigue and headache. ENT diseases could be highly interrelated with these major cases as immune systems were down. Two health problems were in the moderate case category, they were emotional disease (17.3\%) and skin or dermatology $(15.5 \%)$ disease. These suggested that construction workers were prone to emotional diseases and skin problems when working in construction-related environment. Root causes to all these pollutions should be further determined to reduce the occurrence. All the other health problems surveyed had less than $10 \%$ of occurrence, they were health problems such as sick building syndrome, respiratory, gastrointestinal, difficulty to focus, tendency to faint, and difficulty to walk or move in long hours.

There were only a total of $21.2 \%$ of site-based construction workers responded to this survey with only $4.2 \%$ coming from the blue-collared labour. This was the limitation of this study where the respondents were largely office-based. The low response rate from the site-based construction workers could have undermined the criticality of some of the health problems. For instance, hand arm vibration and noise-induced hearing loss affected were affecting the blue-collared labour interviewed. Their job nature involves intensive and repetitive actions like 
hammering, drilling, welding and the like. The exposures to noise, debris, particles and continuous fixed position when operating construction tools are what that have contributed to the health problems like HAV and NIHL.

These findings captured a clearer preliminary understanding on the health problems affecting Malaysian construction workers. The data is useful for further investigation on the health problem itself and solutions to provide a better safety measures for prevention. These can lessen the work-day loss and eventually economic loss.

\section{CONCLUSION}

The aim accomplished in this research study was to obtain the figures of the highest and the lowest health problem occurrences among construction workers working in construction environment in Malaysia. The top health problems that construction workers were facing were musculoskeletal disorders and ear, nose and throat diseases. With over $70 \%$ of occurrence among construction workers, these were the pressing health issues that employers should be concerned of in order to lower the probabilities of compromised safety at work. Construction industry has a dirty, difficult and dangerous working environment. Labour, especially the blue-collared, is prone to accidents if they are allowed to work even when they are not feeling well. Any health check procedure for construction workers implemented by employers can be relooked for the many benefits like timely project delivery, positive health and safety reputation, and low work-day loss. The authors hope to further study on the pressing health issues related to both office-based and site-based construction workers with more respondents from site-based workers. It is also worthwhile to investigate the cost and benefit of construction workers' health problems and treatments provided associated to construction projects.

\section{REFERENCES}

Ali, A., Kamaruzzaman, S., \& Sing, G. (2010). A Study on causes of accident and prevention in Malaysian construction industry. Editorial Board/Sidang Editor.

Arndt, V., Rothenbacher, D., Daniel, U., Zschenderlein, B., Schuberth, S., \& Brenner, H. (2005). Construction work and risk of occupational disability: a ten year follow up of 14474 male workers. Occupational and environmental medicine, 62(8), 559-566.

Baker, E. L., Dagg, T., \& Greene, R. E. (1985). Respiratory illness in the construction trades. I. The significance of asbestos-associated pleural disease among sheet metal workers. Journal of Occupational and Environmental Medicine, 27(7), 483-489.

Boschman, J. S., van der Molen, H. F., Sluiter, J. K., \& Frings-Dresen, M. H. (2012). Musculoskeletal disorders among construction workers: a one-year follow-up study. BMC musculoskeletal disorders, 13(1), 1.

Boschman, J. S., Van der Molen, H., Sluiter, J., \& Frings-Dresen, M. (2013). Psychosocial work environment and mental health among construction workers. Applied ergonomics, 44(5), 748-755.

Bourque, L. B., Fink, A., Fielder, E. P. (2003). How to conduct self-administered and mail surveys. Sag Publications Inc., Thousand Oaks, California.

Cavallari, J. M., Fang, S. C., Eisen, E. A., Mittleman, M. A., \& Christiani, D. C. (2016). Environmental and occupational particulate matter exposures and ectopic heart beats in welders. Occupational and environmental medicine, oemed-2015-103256.

Dillman, D. A. (2000). Mail and internet surveys: the tailored design method, Second Ed. John Wiley and Sons, Inc., United States of America.

Economy Watch. (2010). Construction industry trends. Economy Watch Retrieved from http://www.economywatch.com/world-industries/construction/trends.html

Goldenhar, L. M., Hecker, S., Moir, S., \& Rosecrance, J. (2003). The "Goldilocks model" of overtime in construction: not too much, not too little, but just right. Journal of safety research, 34(2), 215-226.

Hamid, A. R. A., Majid, M. Z. A., \& Singh, B. (2008). Causes of accidents at construction sites. Malaysian journal of civil engineering, 20(2), 242-259.

Health and Safety Executive. (2015). Health and safety in construction sector in Great Britain. Retrieved from http://www.hse.gov.uk/statistics/industry/construction/

House, R. A., Sauvé, J. T., \& Jiang, D. (2010). Noise-induced hearing loss in construction workers being assessed for hand-arm vibration syndrome. Canadian Journal of Public Health/Revue Canadienne de Sante'e Publique, 226-229.

Hsu, D., Sun, Y., Chuang, K., Juang, Y., \& Chang, F. (2008). Effect of elevation change on work fatigue and physiological symptoms for high-rise building construction workers. Safety science, 46(5), 833-843. 
Hu, B. S., Liang, Y. X., Hu, X. Y., Long, Y. F., \& Ge, L. N. (2013). Posttraumatic stress disorder in co-workers following exposure to a fatal construction accident in China. International journal of occupational and environmental health.

Jafari, N., \& Dehghani, M. (2016). Signs and symptoms of sick-building syndrome among office workers of Bandar Abbas Municipality. Journal of Exploratory Studies in Law and Management, 3(1).

Lacourt, A., Pintos, J., Lavoué, J., Richardson, L., \& Siemiatycki, J. (2015). Lung cancer risk among workers in the construction industry: results from two case-control studies in Montreal. BMC public health, $15(1), 1$.

Leung, M.-y., Liang, Q., \& Yu, J. (2016). Development of a mindfulness-stress-performance model for construction workers. Construction Management and Economics, 1-19.

Mansor, N., Zakaria, N. H., \& Abdullah, Z. (2011). Understanding common dimensions of workplace accident in Malaysia. Business and Management Review, 1(6), 22-33.

Nunnally, J., Bernstrein, I. (1994). Psychometric theory, Third Ed. McGraw-Hill, New York.

Sauni, R., Toivio, P., Esko, T., Pääkkönen, R., \& Uitti, J. (2015). Effective information campaign for management of exposure to hand-arm vibration in the metal and construction industries. International Journal of Occupational Safety and Ergonomics, 21(2), 158-165.

Sekaran, U., Bougie, R. (2010). Research Methods for Business: A Skill Building Approach. 5th ed. United Kingdom: John Wiley \& Sons Ltd.

Serrano, M.-A., Cañada, J., \& Moreno, J. C. (2013). Solar UV exposure in construction workers in Valencia, Spain. Journal of Exposure Science and Environmental Epidemiology, 23(5), 525-530.

Stocks, S., Turner, S., McNamee, R., Carder, M., Hussey, L., \& Agius, R. (2011). Occupation and work-related illhealth in UK construction workers. Occupational medicine, kqr075.

Tadesse, S., \& Israel, D. (2016). Occupational injuries among building construction workers in Addis Ababa, Ethiopia. Journal of Occupational Medicine and Toxicology, 11(1), 16.

Thomas, D., \& Frankenberg, E. (2002). Health, nutrition and prosperity: a microeconomic perspective. Bulletin of the World Health Organization, 80(2), 106-113.

Yilmaz, F., \& Çelebi, U. B. (2015). The Importance of Safety in Construction Sector: Costs of Occupational Accidents in Construction Sites. Business and Economics Research Journal, 6(2), 25.

Zakaria, N. H., Mansor, N., \& Abdullah, Z. (2012). Workplace accident in Malaysia: most common causes and solutions. Business and Management Review, 2(5), 75-88. 